\title{
COMMENTARY
}

\section{Increased complexity of vasopressin's vascular actions}

\author{
Donald W Landry ${ }^{1}$ and Juan A Oliver2* \\ See related research by Rehberg et al., http://ccforum.com/content/14/6/R200
}

\begin{abstract}
Vasopressin is becoming a widely used pressor in conditions with severe hypotension. Like several other hormones important in cardiovascular and extracellular fluid control, however, vasopressin can activate several receptors that when pharmacologically or pathologically stimulated may result in conflicting effects. In the present issue of Critical Care, Rehberg and colleagues examined the hypothesis that blockade of vasopressin V2 receptor during septic shock may be beneficial. Their tantalizing results indicate that future work must consider the precise vasopressin receptors that are stimulated and/or inhibited.
\end{abstract}

It is now established that activation of two vasopressin receptors located in the circulation, V1-R and V2-R, causes opposite vascular effects; that is, vasoconstriction and vasodilation, respectively. Hence, Rehberg and colleagues examined whether a V2-R blocker may prevent vasodilation and help maintain cardiovascular homeostasis during septic shock [1].

Vasopressin has long been recognized to have very potent vasoconstrictor action in isolated vascular preparations, but when infused in vivo under normal conditions vasopressin increases blood pressure only modestly at best. In addition, development of vasopressin's vasoconstriction blockers a few decades ago showed them to be ineffective in lowering the blood pressure of most forms of hypertension. Unsurprisingly, therefore, there was little interest in vasopressin's vascular action until our report that some patients with prolonged vasodilatory shock had inappropriately low plasma vasopressin levels and that administration of exogenous hormone quickly restored blood pressure [2]

*Correspondence: jao7@columbia.edu

2Department of Clinical Medicine, 630 West 168th Street, P\&S 10-441, New York,

NY 10032, USA

Full list of author information is available at the end of the article
Like most hormones involved in blood pressure and extracellular fluid control, however, vasopressin has several receptors that regulate different functions. Vasopressin's vasoconstriction action is mediated by the V1a receptor, V1a-R, located in vascular smooth muscle. The second vasopressin receptor (V2-R) is abundantly present in the collecting duct, where it mediates the hormone's antidiuretic action. While the role of this receptor outside the kidney is less well understood, it is known to be located in the endothelium and pharmacological studies have shown that its specific activation in the circulation induced vasodilation and hypotension and the release of the coagulation factors VIIIc and von Willebrand factor. These findings suggest that the use of vasopressin as a pressor in clinical medicine could be made safer and perhaps more effective using selective activation of V1a-R or blockade of V2-R.

In this regard, in two recent studies where a selective V1a-R agonist was compared with exogenous vasopressin during septic shock, the former was found to be of superior benefit than the natural hormone, which, needless to say, stimulated both V1a-R and V2-R [3,4]. These provocative experiments suggested that administration of exogenous vasopressin to maintain blood pressure in septic shock is complicated by stimulation of receptors with conflicting function. Moreover, because - as in the early phase of sepsis - endogenous plasma vasopressin can reach exceedingly high levels [5], it is also possible that stimulation of the V2-R by endogenous hormone could in fact contribute to the disease process.

Accordingly, Rehberg and colleagues examined the hypothesis that administration of a V2-R-specific blocker during the early phase of septic shock may have a beneficial effect (that is, be more effective in maintaining cardiovascular homeostasis than placebo) or may be superior to administration of exogenous vasopressin. Briefly, they induced septic shock in sheep by intraperitoneal injection of feces and, upon development of hypotension, animals were randomly assigned to receive vehicle, vasopressin or the V2-R antagonist [1]. If needed, animals were given open-label norepinephrine to maintain mean arterial pressure at $\sim 70 \mathrm{mmHg}$. The study 
contains much interesting data, but we focus on its more important results. First, the amount of norepinephrine needed to maintain mean arterial pressure was no different among the groups. There was a statistically significant increase, however, in the survival time for the group of animals receiving the V2-R blocker when compared with those receiving placebo or receiving vasopressin. In concordance with this finding, the animals treated with the V2-R antagonist displayed less severe lactic acidosis as well as oxidative stress. Finally, the authors made the intriguing observation that the plasma levels of vasopressin were markedly reduced in the animals receiving the V2-R blocker.

What are we to make of these observations? Since the dose of norepinephrine needed to maintain blood pressure was similar in all groups, we can conclude that in the early phase of septic shock - when plasma levels of vasopressin were endogenously increased (in the animals receiving placebo) or increased by administration of exogenous hormone - a potential vasodilator action of the V2-R is unlikely to have contributed to determine the blood pressure. Had this been the case, the animals receiving the V2-R blocker would have required less norepinephrine. Nonetheless, this group of animals had longer survival as well as metabolic evidence of less severe disease. The explanation for this benefit is a matter of speculation: improved cardiovascular homeostasis (higher left ventricle stroke index and central venous and pulmonary artery occlusion pressures with V2-R blockade were observed); inhibition of vein dilatation; prevention release of coagulation factors thereby retarding development of capillary thrombosis; and reduction of endothelial nitric oxide release with diminution of reactive oxygen species.

Concerning the very interesting finding that plasma vasopressin levels dramatically decreased in animals with V2-R blockade, as Rehberg and colleagues note, in vitro experiments [6] and in vivo experiments [7] indicate that vasopressin has a positive feedback on its own secretion that appears to be V2-R mediated. This intriguing finding needs confirmation.

In sum, this work is a valuable addition to the emerging literature on the mechanisms of action of vasopressin during septic shock and highlights for the first time a role of V2-R. This work makes it clear that future research on vasopressin's role in septic shock needs to take into account the precise vasopressin receptors that are stimulated and/or inhibited.

\section{Competing interests}

The authors declare that they have no competing interests.

\section{Author details}

'Department of Medicine, 622 West 168th Street, PH 8-East, Room 105, New York, NY 10032, USA. ²Department of Clinical Medicine, 630 West 168th Street, P\&S 10-441, New York, NY 10032, USA

Published: 13 December 2010

\section{References}

1. Rehberg S, Ertmer C, Lange M, Morelli A, Whorton E, Dünser M, Strohhaecker A, Lipke E, Kampmeier TG, Van Aken H, Traber DL, Westphal M: Role of selective $\mathrm{V}_{2}$-receptor-antagonism in septic shock: a randomized, controlled, experimental study. Crit Care 2010, 14:R200.

2. Landry DW, Levin HR, Gallant EM, Ashton RC Jr, Seo S, D'Alessandro D, Oz MC, Oliver JA: Vasopressin deficiency contributes to the vasodilation of septic shock. Circulation 1997, 95:1122-1125.

3. Traber, DL: Selective V1a receptor agonists in experimental septic shock. Crit Care 2007, 11(Suppl 4):P51. doi:10.1186/cc6030.

4. Rehberg S, Ertmer C, Vincent JL, Morelli A, Schneider M, Lange M, Van Aken H, Traber DL, Westphal M: Role of selective V1a receptor agonism in ovine septic shock. Crit Care Med 2010. [Epub ahead of print]

5. Wilson MF, Brackett DJ, Tompkins P, Benjamin B, Archer LT, Hinshaw LB. Elevated plasma vasopressin concentrations during endotoxin and $E$. coli shock. Adv Shock Res 1981, 6:15-26.

6. Landgraf R, Ramirez AD, Ramirez VD: The positive feedback action of vasopressin on its own release from rat septal tissue in vitro is receptormediated. Brain Res 1991, 545:137-141.

7. Wotjak CT, Ludwig M, Landgraf R: Vasopressin facilitates its own release within the rat supraoptic nucleus in vivo. Neuroreport 1994, 5:1181-1184.

doi:10.1186/cc9344

Cite this article as: Landry DW, Oliver JA: Increased complexity of vasopressin's vascular actions. Critical Care 2010, 14:1011. 